\title{
Historein
}

Vol 4 (2003)

Public Histories

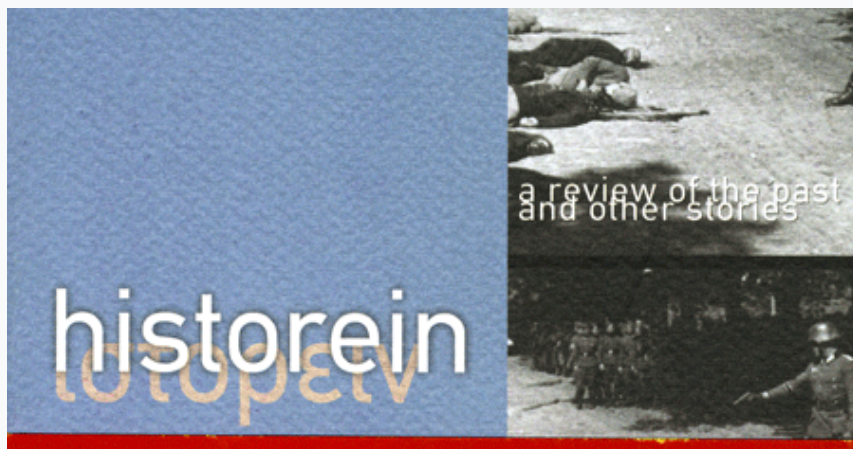

\section{History in the Digital Domain}

Mark Poster

doi: $10.12681 /$ historein.82

Copyright $\odot$ 2012, Mark Poster

\section{(ㅇ) $\odot \odot \bigcirc$}

This work is licensed under a Creative Commons Attribution-NonCommercialShareAlike 4.0.

To cite this article:

Poster, M. (2004). History in the Digital Domain. Historein, 4, 17-32. https://doi.org/10.12681/historein.82 
History

\section{in the Digital}

Domain

Mark Poster

\section{Digital Disciplines}

What is at stake in the alteration of material structure of cultural objects from the paper forms of manuscript and print to the digital form of computer files? In particular, how is the change affecting academic disciplines which rely upon stable forms of symbolic records? More specifically still, how is the discipline of history affected by the digitization of writing? Is digitization simply a more efficient means of reproduction, storage and transmission of documents, whose availability in space and time is enhanced for the application by historians of research techniques and methods? Or does digitization cause an alteration for historians in the constitution of truth?

Katherine Hayles suggests that digital culture introduces into the epistemological procedures of the humanities and social sciences a logic of pattern and noise, one that contrasts with an older logic of presence and absence (Hayles, 1993, 387). In the digital domain of zeros and ones (Plant, 1997), everything is in principle immediately present and at the same time always distant, mediated by information machines. Digital information is on the server, in cyberspace, on the hard disk, in RAM, never palpable to beings ensconced in a Newtonian universe. By contrast, in the world of atoms, an epistemology of presence and absence prevailed at least since Plato introduced a hierarchy in which voice receives privilege over writing. In the domain of atoms - let us call it for convenience, the analogue world - truth consists in a certain relation to presence, either presence in the consciousness of an embodied speaker, or in the representation of that con- 
sciousness in voice, or, finally, in the representation of that voice in a printed or handwritten text. The epistemology of the analogue, or its ideology if you prefer, is that of an original defined as subsisting in consciousness: truth exists in consciousness in the first instance. Voice, handwriting, and print sustain that epistemology through the supplement of representation. Derrida's critique of this epistemology inserts deferrals in time and space within the ideology of presence, revealing its repressed underside as the position of absence. Deconstruction remains within the epistemology of presence/absence, complicating its intentions, reversing its priorities, unsettling its metaphysics of the origin, without, however, discarding its terms.

If digital culture constitutes an epistemology of randomness/pattern, it inserts a new logic of truth within a cultural world caught up in an older binary of presence/absence. One might say that now, in the era of information machines, in an age when cultural objects reside within such machines, the strategy of interpretation shifts to the question of the pattern within the noise. Truth cannot find its origin in consciousness but in the interpretive process that shifts patterns from a background of noise. One might then also go along with Neal Stephenson in Cryptonomicon [Stephenson, 1999] and give priority in the question of truth to the decoding of messages, to the extraction of patterns from the devised noise of encrypted signs. In this case, one knows that a pattern exists, but the agent that formed the pattern is so removed from the presence of the signs - through the machinic mediation, through the encoding process, etc. - that decoding must look to the pure text, to the array of signs and apply methods like statistics and other algorithms that do not suppose an originating consciousness but only a pattern related to a language. Encrypted messages constitute a heaven of structuralist linguistics, one where meaning pertains solely to the string of symbols.

Epistemology is then complicated first by the deconstructive move to reverse the binary of presence/absence, then by the addition of the binary pattern/randomness. At issue is not the displacement of analogue truth systems by digital truth systems but the establishment of a field where both are at play, independently and in mixed forms. We have then a very messy situation confronting us.

\section{Disciplining the Discipline}

In this messy situation, with so much in the humanities appearing up for grabs, uncertain and in turmoil, the ability of the discipline to respond to the challenge and opportunities of new media depend in part on how tightly the boundaries of the discipline are guarded, or how open historians are to new developments affecting their methods and assumptions. From the 1970s to the 1990s, the discipline of history shifted interest toward the social and the everyday, away from grand politics and intellectual history. Although many of these younger historians were Marxist in orientation, the empiricist epistemology that characterized political history changed very little in the shift to social history. Social historians, like their forebears, searched the record for con- 
scious acts of agents (Poster, 1997,101). Despite the shift of field to the social, historians, clinging to established methodologies, defensively rejected the theoretical innovations that coursed through the humanities in the last third of the century. Borders of the discipline were closed to any hint of "fiction," of questioning the objectivity of the past, of introducing critically oriented theories, and self-reflection on assumptions. Those who insisted upon doing so, like Hayden White, generally found themselves shunned or marginalized. Remarkably, the same conclusion may be drawn concerning another shift of emphasis in the discipline: the turn in the 1990s to cultural history and global history. Although the field of inquiry is now radically different from what it was in the 1950s and 1960s, the epistemological rules remain the same.

A question that follows from this summary of the state of the discipline is who qualifies as a bona fide historian? As new media challenge many of the habits of the discipline, it is urgent to inquire about the readiness of the discipline to face what might be perceived as strange new procedures of inquiry. In this vein, most often academics in history departments will respond to the question of membership in the guild, "Only those who have a PhD from a history department." But at least in three quite prominent recent cases, Edward P. Thompson in British social history, Arthur M. Schlesinger in the political history of the United States, and Philippe Ariès in the cultural history of France, that criterion would not suffice: none earned a PhD in history. ${ }^{1}$ In another criterion of qualification, many scholars from disciplines other than history write books which are taught in history courses at universities. These important exceptions to conventional judgment - and there are many more examples like them such as Herodotus and Thucydides - encourage us not to sluff off the question with statistical probabilities but open it to fresh inquiry.

If it is not possible to guarantee with certainty the historian's identity, perhaps an easier question might be, what qualifies as a work of history, as historical knowledge or truth? A simple answer might be those works which are accepted as such by historians. But then we are in an awkward logical circle, as the reader/listener might have noticed. In my experience, faculty in history departments that offer PhDs in history often utter, in relation to papers by students and even published works, the phrase "that is not history." This comment pertains not to the question of the coherence of the students' texts or the quality of their research effort but rather to the theoretical aspect of their work. Historians habitually draw a boundary around their discipline, excluding from it scholarly works which at least on the surface are historical in the simple-minded sense that they are about the past. In fact one might, with Foucault, designate the phrase "that is not history" as a discursive "rule of formation" of the discipline (Foucault, 1972, 529). Students are often told in no uncertain terms that their work is "not history" when they deploy in their texts theories from poststructuralists, for example.

Here are some instances of the problem from my own experience. In a job talk at my university a young historian presented a paper on the historical conditions of Lacanian psychoanalysis in the 1920s, the relation of the emergence of French psychoanalysis with legal institutions. Distin- 
guished members of the department voted against hiring her using the argument that Lacan "is not history." In another instance, a graduate student at the University of Toronto told me that her adviser urged her not to include Foucault's name in her dissertation, not even in a footnote, because "that is not history." Or again, some years ago I presented to my department the proposal of a distinguished colleague from the department of French literature at my campus who wanted to give a course in the history department on the relation of history to literature in the eighteenth century, an age when the demarcations between the two discourses was murky at best. This was an easy one: many colleagues demurred with the phrase "this is not history." And one more example: while attempting to qualify with enough undergraduate credits for entry into a graduate program in history, I took a course in 1963 on European history at St. Johns University in Queens, New York from an instructor who was also a priest in the Catholic Church. He announced to the class, much to my naive surprise, that prominent historians of the day (he mentioned the most distinguished American historian of France of the day, R.R. Palmer of Princeton University), regarded two categories of scholars as automatically "not historians": Communists and Catholics. Although such judgments are not often aired in official journals and at panels of the convention of the American Historical Association, they are commonplace in the practice and decisions, in the institutional activity, of history departments. Keeping the boundary of history defended against fiction, theory, non-Protestants, non-liberals is the difficult work of the gatekeeper. These personal examples illustrate, I hope, not that gate-keeping ought to be abolished but that historians have an overly narrow sense of what may be included within their safe boundary. So today, when digital culture introduces its new conditions of truth, the discipline of history may need to rethink the location of its Maginot line. It may behoove historians to redefine who and what are included in their club.

\section{Historical Data}

The digitization of texts, images, and sounds presents several levels of problems for defining the nature of historical truth. The first concern in the minds of most historians is the fate of data that originally existed in print or manuscript forms now located in digital files on the internet. Roy Rosenzweig has shown how quickly historians have converted documents into digital files and posted them on the internet ("The Road to Xanadu: Public and Private Pathways on the History Web," Journal of American History 2001, 88 (2), 548-579). One major archive, American Memory, the online resource of the Library of Congress's National Digital Library Program (NDLP), contains over five million records. Full text digital versions of countless academic journals are available, from historians especially from JSTOR and Project Muse. Thousands of sites have been constructed on the web by teachers of history and history enthusiasts, by Civil War re-enactors, family genealogists, and other groups achieving high numbers. These sites are constructed by a combination of professional historians and amateurs, raising the question of verifiability of documents to a new level of urgency. It is often not clear if documents on the web have 
been put there by those holding PhDs in history. The pedigree of web sites is notoriously uncertain. Nonetheless these sites, which are sometimes very popular, contain a rich trove of text, images, and sounds.

In addition to worries about authenticity, another troubling aspect of history-on-the-web is the increasing privatization of document collections and, even worse, the increasing concentration of media companies owning these databases. In a sense, access to historical documents has always presented difficulties for the scholar. Collections are often controlled by governments, corporations, and private individuals who may be reluctant for various reasons to open them to researchers. One skill not taught in graduate school but essential for historians concerns strategies for overcoming obstacles to such collections. Legal hurdles are often most burdensome: copyright law, in one stroke, prevents access to vast classes of documents. Yet digitization changes the nature and extent of the difficulties. Since it renders distribution and copying cost free, the internet lightens the burden of many research chores. From home one can access countless documents and locate information with great ease. Yet the great advantages of digital culture put in question many of the established systems of control. In response, the music and film industries lobbied hard to undermine the best features of the internet with the passage in 1998 of the Digital Millennium Copyright law which significantly expanded corporate control of culture and, for historians, reduced access to data collections. ${ }^{2}$ Digital culture thus opens a new political dimension to access, one that seriously affects historians, although I am not aware of any response to the DMC by the American Historical Association. In the first instance, then, digitization changes the nature of historical documents by rendering them easily available, introducing new questions of certification, and opening the issue of access to direct and controversial political questions.

A second aspect of the digitization of data is that it renders all documents potentially fluid, changeable at the whim of the reader/viewer/listener. At present many digital document formats are closed. Certain hypertext novels, for example, can be read and the reader can add "links" but the nodes of story cannot be changed. Also, Adobe's pdf format forbids alteration of the document and additionally prevents cutting and pasting of passages. Many of the books and articles that have been digitized and are available online come to readers in pdf format. JSTOR articles and Netlibrary books are in pdf. Using such closed formats perhaps facilitates the widespread distribution of documents but preserves their original forms, some would say, their integrity. Inured to print media and paper formats, modern culture has for centuries abided closed formats. But digital culture lends itself more readily than print and broadcast media to open cultural objects, to the simultaneous reading and rewriting of texts, viewing and reimaging of pictures, and listening and transforming of auditory items. Word processing, image viewing, and audio programs all enable the position of audience to become, at the same time, the position of author, artist, and composer. Furthermore, the network of digital objects encourages these figures to 
become distributors. Functions that were separate in the print and broadcast ages of media, now are merged or at least have their boundaries blurred. Digital culture introduces principles of reception that echo the era before mechanical reproduction: the traditions of oral story-telling and folk music in which each reception was also a transformation. In the digital mode, these practices, once limited to the proximity of voice, now may disseminate globally. As a result, historical documents face a danger of losing their "integrity" and becoming open to continual transformation, surely a nightmare for historians.

\section{Digital Archives}

The archive has been central to the epistemology of history from its inception. For historians, travel to archives in the nineteenth century was analogous to fieldwork for anthropologists, a sine qua non of professionalization. Archives gained new importance beginning in the 1970s with the trend toward social history. If nineteenth century historians, given the salience of history in the nation state, consulted the collections of governments, late twentieth century historians, more concerned with previously ignored groups (the working class, women) and institutions (the family, the labor union) investigated legal documents, church registries, land-holding records. Both political and social historians regarded the visit to the archive as a prerequisite of scholarship, investing in it great emotional energy.

In a pioneering study of the gendered nature of historical practices, Bonnie Smith demonstrates the emotional fascination of historians for archival work. She distinguishes the graduate seminar, characterized by a mood of civic rationality, from the journey to the archive where historians found "love, melodrama, and even obsession" (Smith, 1998, 116). The trip to the archive was most arduous, especially in the nineteenth century. Historians viewed themselves in heroic terms, overcoming dangers, costs, and inconveniences to access ill-sorted records and the authentic traces of the past. In this context, emotions were easily incited. Even the legendary founder of modern history, Leopold von Ranke, was affected. He described his experience in the archive thusly: "Yesterday I had a sweet, magnificent fling with the object of my love, a beautiful Italian, and I hope that we produce a beautiful Roman-German prodigy. I rose at noon, completely exhausted." (119) The archive was the occasion for a most masculine flurry of emotion. Smith concludes her analysis by indicating the imbrication of archives with truth and feeling: "... archives became the richly imagined repositories of knowledge and the guarantors of truth..." (128) One can also conclude that social historians from the 1970s onward, including many women, continue to associate truth with feeling, albeit in a more complex mixture of gendered experience.

The physical form of documents as print and manuscript papers conditioned the architecture of the archive. Papers require an enclosure safe from the elements of nature and papers that are rarely consulted, such as those in archives, likely will be housed in an obscure location and given 
little attention in their arrangement. By their nature archives of paper are off-putting, remote, inaccessible, and poorly organized. Digital archives, by contrast, require no journey at all, only "surfing" with "navigator" or "explorer," metaphors that conceal the absence of travel in space. Such repositories may be "searched" with the ease of database algorithms, with a tap on the keyboard or a movement of a mouse. Information can be extracted from them with simple cut and paste operations of the word processor, not the arduous copying by hand or even machine. The new archive far less likely elicits feelings of heroic conquest in men or analogous emotions in women. Perhaps the digital context will reduce the intensity historians invest in the archive and perhaps they will less likely fall under the illusion, characteristic of earlier generations, that archives contain the truth of the past, that the reassembly of their documents constitutes by itself, to quote Ranke, "the past as it actually was" (Novick, 1988). Perhaps digital archives will lessen the false objectivism of historians and afford a turn to a more self-reflective and constructivist understanding of the historical text.

In other disciplines, such as anthropology, literary criticism, and art history, scholars have begun to investigate the media that contain cultural objects. Museums have attracted much attention in these fields as important constituents of the epistemological practice of the discipline. The way cultural objects are stored and available for reception thus is understood to influence the kind of knowledge produced about them. Jacques Derrida muses about the influence of an email archive on the early psychoanalytic association (Derrida, 1995, 353). His use of the term "archive" is more general or metaphorical than the historians', including in the category any stored collection of information. In this sense, museums and public libraries would also qualify as archives. Using Derrida's definition, an archive denotes a material collection of data and is distinguished from memory, although the brain is certainly a material being and memory changes its chemistry however minutely. If other disciplines than history have been most interested in the functioning of the archive, historians have focused attention on memory. In recent years, they have explored oral history and testimony as a continuation of the trend toward social history but also in new directions such as the question of historical trauma (LaCapra, 1988, 2001). While historians have wrestled with questions of the epistemology of memory, and addressed the comparison of written/print records with oral evidence, they have paid much less attention to the archive and its potential transformation into digital forms.

Curious about the recognition by historians of the importance of the archive to their disciplinary truth, I did some searches of online journals, using the latest technology of the California Digital Library. I searched for the word "archive" in the texts and titles of articles in some of the leading journals of the field: The American Historical Review, History and Theory, the Journal of Modern History, French Historical Studies, and the Journal of Interdisciplinary History. In the AHR going back to the 1960s, there were 119 instances of the word "archive"; in History and Theory (which went back only to 1998) and the Journal of Modern History combined there were 120. A search 
of the other two journals yielded not one result. Of the 239 mentions, only one raised questions about the archive in general in relation to historical truth. One may conclude that, compared to the great interest of historians in the question of memory and its relation to more permanent traces in paper, the media change of the archive has not aroused much concern.

But an older technology yielded slightly better results: an email to a friend asking about the question of digitization of archives resulted in a reference that proved suggestive. ${ }^{3}$ A German scholar, Wolfgang Ernst, compared digital archives with historical narratives in relation to archaeological evidence. He argues that inscriptions on stones from Roman antiquity confront the historian with bits of data, forming a kind of archive, which can only be absorbed in historical narratives by seriously violating the limits of the evidence at hand. He contrasts the mute, modular, partial, highly ambiguous shards of script that constitute a good deal of the "archive" of ancient history, with the pleasingly unified fullness of meaning in historical narratives, underlining "the dissonance between analytical archaeology and synthetical history..." (Ernst, 1999, 61) Ernst speculates on a new history that would take its point of departure from hyper-text databases where modules of documents reside in heterogenous juxtaposition. "Maybe the computer has the better memory of the past," he snidely asks. (62) His polemic against narrative history, however, rejoins the profession's objectivist leanings. A synthetic model of archaeology and digital archives, in his mind, is closer to some facticity than the elaborated stories of conventional historiography. Digital archives for him return history to a grounded methodology of fidelity to the documents, the old empiricist saw.

Ernst remains within the binary history/fiction. Perhaps digitization permits a move outside this opposition. Computerized databases suggest the inseparability of the discursive need for narrativizing (introducing "fiction") and the insistence to heed the material form of the information. Digital documents, for instance, require aesthetic choices about the display of the data, even in the matter of keyword indexing that greatly affects access to information. At the same time, digital documents remind the researcher of their inauthenticity, that they are not relics from the past but transcodings of a recent vintage (Manovich, 2001). In these ways, digital archives obey epistemological canons that depart from the familiar rules of usage associated with more conventional sources.

\section{Historians Online}

In addition to the digitization of historical documents, writings by historians are also migrating to computer formats and appearing online. Historians are publishing their work in online journals, print journals are available online, and even monographs and other larger works are being posted to web sites. There are also a number of centers for historical research that treat directly the question of the new media, such as the Center for History and New Media at George Mason University. In all of these ways the writing of historians is increasingly present on the global com- 
puter network. One question persists from our earlier discussion of digital data: how does the user authenticate web sites with historical writing? It is easy enough for someone to copy a piece from my web site and place it on their own, under their own name, perhaps with design alterations. Such acts that were called plagiarism in the age of print (and which instructors are quite familiar with) will likely increase with digitization and the new principle of the variable cultural object.

Digital culture also facilitates new kinds of texts by historians, texts that combine audio and visual components. Multimedia documents are as easy to create as texts. Ted Nelson's vision of "Xanadu," a global, hypertext library, put forth in the mid-1960s (Nelson, 1965) anticipated what has become the reality of the world wide web. Some scholars as in the William Blake Archive edited by Morris Eaves, Robert Essig, and Joseph Viscomi (http://www.blakearchive.org/) put online the poetry of William Blake whose printed texts included drawings that were integral to the reading. They have utilized the web to transfer, as faithfully as possible to the original print versions, work that appeared first in rudimentary multimedia forms. This form of transcoding, however, ignores the difference between print and digital media, taking advantage only of the propinquity of the web as a means of dissemination. Gregory Crane's Perseus Digital Library (http://perseus.mpiwg-berlin.mpg.de/), covering ancient Greek and Latin writing, and others like George Landow whose databases concern the work of Charles Dickens, deployed greater features of digital culture. Landow built multimedia databases including literary works, historical works that relate to the same period, and images from the period (Landow, 1997, 210). As many have argued, the transfer of texts to the web, even limited to the juxtaposition of multiple media and cultural objects in a single database, introduces an associational logic of web space that runs counter to the more linear logic of print. Hypertext promotes jumping from one site to another, with no hierarchical, tree-like structures, such as numbered pages or library catalogue files, to control the narrative of discovery or research. It remains unclear how these features of digital culture - hypermedia and associational links - will affect the construction of historical narratives.

If the material form of the web presents a challenge to the bookish discipline of history, it also poses a threat to the institutional procedures of certification. Anyone, even an undergraduate history major, can publish their work on a web site for all to see. In one respect, Carl Becker's phrase becomes a literal reality: "everyman his own historian" (Becker, 1935, 586). No obstacle stands in the way of publicly displaying historical scholarship. The practice of expert readers and referees in publishing houses and journals is bypassed by digital culture. Ease of publication poses an enormous problem for all the disciplines, including, of course, history. For the student or layperson, the web offers exciting possibilities for distributing historical scholarship; for those in the discipline, the issue is more complex. To what extent will departments and campus review committees accept publication online for credit toward promotions and tenure? As economies of publishing discourage the printing of narrow monographs and revised dissertations, presses are 
beginning to issue "books" exclusively in digital formats. Will these publications earn the status of paper books? And as print journals are appearing in digital form, the lines are blurring between paper and online distribution. Again digital culture destabilizes established traditions of scholarly evaluation and review.

\section{Life Online}

Digital culture presents further difficulties for historians: not only are archives online and historical writings online but social life itself in part occurs on the web and the internet more broadly. Historical experience itself is in part digital. Personal letters take the form of email. A great variety of chat rooms, bulletin boards, electronic cafes and public meeting rooms proliferate on the internet. Guest workers in foreign lands and diasporic peoples in general utilize the internet to maintain daily contact with family and friends back home. Young people expand their social contacts through instant messaging. Online games are a major activity for countless thousands. Wireless telephony is becoming digital. In some places, bandwidth is great enough to afford video conferencing. Millions exchange music files in digital form on the internet. In fact, digital culture is designed for and characterized by remote intimacy, communication mediated by machines, in short, by virtual reality. Interlaced with RL (real life), VR obeys rules that are significantly different from familiar forms of society. Most saliently, the historian's assumption about individual and group agency is sharply challenged by social encounters heavily mediated by networked computing, by information machines. The interface of the net, where no one ever knows for sure who you are, presents an enormous problem of theory and methodology. How will historians write the history of life on the screen when it is uncertain who is acting and to what extent is the actor a human being acting, a machine or some combination of the two?

\section{An Example from Ethnography}

One of the richest and most nuanced studies of social experience on the internet is Don Slater and Daniel Miller's ethnography of internet use in Trinidad, The Internet: An Anthropological Approach. Based on interviews with Trinis in the late 1990s, the book contains numerous surprises: In Trinidad, the internet is not understood as an extension of American imperialism, but as a facility completely adaptable to local conditions. Trinidad, as a third world nation, nonetheless has very high internet usage. The only social category left out of internet culture is the older population, a demographic trait that cuts across all nations. Trinis do not see the internet as an intimidating, arcane technology but as easily assimilable to their existing cultural patterns. At the time of the study fully one-third of Trinis had internet access at home and internet cafes were ubiquitous in the urban landscape (Miller, 2000).

Miller and Slater provide a comprehensive overview of internet use in Trinidad: which groups use it and how, which aspects of the internet are most heavily used, how the political economy of 
Trinidad relates to the internet, and, above all, how the history and culture of Trinidad link up with internet use. They argue that the long history of Trini diaspora creates conditions ripe for internet use: since Trinis are unusually dispersed around the globe they have a need for a cheap means of communication such as the internet. The internet enables, they claim, a solidification of the ethnicity of Trinidad. Further, they show how Trinis represent themselves to the world by web pages and other features of the internet, another way that the internet strengthens local identity. Finally, they contend that Trinis received the internet as matching and enhancing local cultural practices. They practice "liming": "filling one's time with skilled banter, dancing and drifting onwards to other places (a street corner, a club, someone's house, another island)... It was regularly cited as the Trini pleasure they most wanted to recover on or through the internet." (89) And they did so in emailing and in chat rooms. The internet for Trinis was not a strange technology that was learned with difficulty and seen as altering their behavior. Use of the internet flowed directly from pre-existing cultural habits.

This very sketchy outline of Miller and Slater's surprising findings indicates the importance of empirical studies of internet use. Their results contradict most assumptions about new media. However, their work points to a problem with such inquiry: they proceeded from the assumption "that we need to treat internet media as continuous with and embedded in other social spaces..." (5) In other words, they assume that the distinction between the virtual and the real presents no epistemological hurdle to their investigation. Continuing from there, they simply interviewed Trinis about their use of the internet. They inserted into their study the figure of the rational agent, one who deploys technologies, engages in practices, expresses cultural forms, and has full selfunderstanding of those experiences. Historians will find this agent convincing since it is the chief narrative conceit of historical writing. Yet it begs the very question that needs to be asked when humans engage with information machines and digital culture, to whit, what are the alterations in the cultural construction of the subject under such conditions? This question might not be answerable by historical agents who appear to have every motive to disavow it. If cultural practices generally tend to work at the unconscious level, then profound changes in cultural modes are even more likely to go deliberately unrecognized, if I can use that oxymoronic phrase. In the present case, Trinis know that they are Trinis but as agents cannot recognize that they became that way and are sustained in that identity through discursive practices embedded in fields consisting of relations of force. How likely would it be, then, for Trinis or any other group, to ask, how, when I am chatting on the net, do I know that my conversant is a Trini, and how, under those conditions, can I represent my true Trininess?

The historical and social science study of the media often concentrates on "effects," such as, does a certain TV show which depicts violence, lead to violent acts by viewers? Or even, does the reporting in the media of actual violence in society, increase its incidence, as in copycat violence? These studies contain a dubious epistemological assumption of a sensationalist theory of 
action - sense data from outside is internalized by the subject, leading in some cases, to its reproduction. This epistemological principle becomes even more questionable, I contend, in relation to the internet. Sensationalist theories of truth presuppose a pre-media agent who is affected by information as an external force. Cultural and social practices are far more complex than that. In any case, the image of the subject presumed by such research is contravened by the multiple marriages of human and machine in digital cultures. We need, instead, to study the links and assemblages of humans with various media. Our categories are profoundly humanist and need to be modified to account for such mediated social experience.

Finally, there is a still more difficult question: digital culture mixes into other media cultures and face-to-face relations, situations where humans are proximate and deploy primarily language as a medium. Humans are now going in and out of various different configurations of media situations. Questions then arise about how these transitions are managed and how each media experience affects the others. One study that approaches this multi-media condition is Nancy Baym's work on soap operas. Her text is noteworthy especially for its comparison of television viewing with Usenet participation, a broadcast and a digital medium, along with telephone conversation and proximate, voice dialogue. The book provides a model of how to approach the dense mediascape of the current conjuncture (Baym, 2000).

One last issue that I would like to call to the attention of historians and social scientists is the following: when you study the archive of a chat room in the effort to comprehend life online, all you have is the digital script, a script that does not represent a social act, but rather is that social act. True enough, reading a chat room archive misses the flow of text on the screen, which often combines several conversations in fast moving and intertwined complexity. But in any case such a text is quite different from, say, a transcript of a courtroom trial. The latter is a record of spoken dialogue by co-present agents concerning prior actions. The former has no external referent: the archive is the entirety of the encounter or exchange. The agents in the chat room exist, while they are there, solely by their textual interventions. Language in the chat room, mediated by networked computers and software programs, constitutes the agent in the act of enunciation and only thereby. What analytic categories, one might ask, are required to render intelligible such a human/machine interface? What ontology of subject and object are capable of rendering coherent these bizarre, monstrous engagements?

\section{Teaching History with Digital Technology}

Digital culture upsets standards of the teaching of history in every way imaginable. Steeply rising anxiety over web plagiarism, the emailing of questions to professors, posting of student work on web pages, online evaluation and testing of students, online research and submission of work in the form of new media, distance learning - in these and many other ways, digital culture offers innovations in higher education at every level. Some of these innovations are relatively innocu- 
ous, like downloading online research or the use of email or listservs to facilitate the administration of the class. Other changes, on the contrary, promise to transform basic aspects of the disciplines. The ease of students' exchanging and posting their own work introduces potentially fundamental alterations of educational experience. More cogently still, research on the web introduces a logic of association, a horizontal epistemology of a "flat" discursive regime in which every site is equal, depending on the protocols of the search engine rather than on intrinsic quality or financial support. This replaces the hierarchical or vertical search logic of the card catalogue, the layout of the library, the linear material organization of the book, or the judgment of the professoriate and the discipline. In addition to the leveling effect of web architecture, digital culture promotes an epistemology of the link and module. What becomes interesting in digital text is not so much the string of symbols but the connections made most often between pre-existing cultural objects, be they text, sound, or image. In the analogue world, higher education promoted truth regimes of argument, rhetoric, comprehensiveness of research, and the like. How will teachers inured to these epistemological habits evaluate a link between a picture and a module of text taken from some document? Will such a link even be considered an accomplishment of learning?

Historians are probably no better or worse than faculty in other disciplines in adapting to the classroom of the digital age. One aspect of the new circumstances that has achieved some attention is the creation of online learning tools. There are many examples of highly successful web pages designed by faculty and graduate students to promote historical education. One thinks immediately of the University of Virginia Center for Digital History, with its projects on "the Valley of the Shadow" (concerning the civil war), "Virtual Jamestown" (an online tour of the colonial city), various digital databases such as "Virginia Runaways Project" (on escaped slaves) and "the Dolly Madison project" (a multi-media database about the president's wife). Countless historians have produced excellent teaching tools that, generally speaking, are open to all teachers in the field. One can only applaud these experiments in digital historical culture.

But other aspects of the application of digital culture to higher education may be less worthy of praise. In the field of distance learning there are also many important experiments. But here there are also serious dangers. Pecuniary impulses, so unconstrained in American culture, combine with digital technology to produce software packages for distance learning that undermine the basic principles of education, critical inquiry, and academic freedom. The advent of digital culture has encouraged some entrepreneurial types to view higher education as a potential market. Heedless of educational culture, these companies imagine they can improve on the efficiency with which information is transmitted from the mind of the teacher to the mind of the student. They need only capture the mind of the teacher in a digital recording system and transfer it to a software system by which it can be commodified and sold. This perversion of education is facilitated by digital culture and must be resisted by faculty in all disciplines. 


\section{History as Media History}

The drastic novelties of digital culture suggest, at the very least, that the history of the media becomes a major topic for historians. This relatively harmless innovation in the epistemological repertoire of the discipline ought to incite far less resistance than some of the other suggestions offered in this paper. Students of media from other disciplines would benefit greatly from comparative historical work. Too many studies of the internet, for example, are flawed by a lack of perspective on the topic, becoming lost in the dazzling novelty of the new technology. Some important work has already been done on topics ranging from print (Johns, 1998), to the telegraph (Carey, 1989), photography, panoramas and other visual technologies of the nineteenth century (Crary, 1992, 345), the telephone (Fischer, 1992), film (Charney, 1995), radio (Douglas, 1987), television (Spigel, 1992) and others too numerous to mention. Not all these histories, it might be noted, are by historians.

Despite the appearance of many noteworthy studies in media history, constituting the field of the history of the media will be no easy task. One issue concerns the relation of media to one another and the relation of new media to old media. Bolter and Grusin have put forth an interesting hypothesis they call "remediation" (Bolter, 1996), the complex way new media attempt to disavow their novelty and assert it at the same time. More than this, the question of the history of information machines, culminating so far in digital media, concerns issues of the materiality of the media, the relation of media to agents, the interface of subjects to objects, the question of humans to machines, the alteration of space/time configurations, the issue of artificial life and the changing boundary between life and non-life, and a plethora of other problems that fundamentally reconfigure the objects of historical analysis, the figure of the historian as subject of history, and the status of history as a truth regime. Media history raises no less a question than the history of the human and the non-human (Guattari, 1993). Digital culture, after all, imposes the question of information machines as agents, placing agency itself in question, a hard nut for historians to confront. Finally, the rapid pace of the introduction of digital culture suggests another kind of problem, one that I do not believe historians until now have dealt with: rapid change of media implies a rapid change of analytic categories, leading to the recognition of the tentative nature of such epistemological tools. We are thus well outside the binary certainty/relativism, and in a new age of conditional truth regimes, a far cry from history "as it actually was." 
${ }^{1}$ Of the three, only Schesinger held a post in a history department.

${ }^{2}$ Benedict (1986) discusses these issues regarding the revision of the Copyright Law of 1976.

${ }^{3}$ The person in question is Dominick LaCapra who I thank for the reference.

\section{REFERENCES}

Baym, Nancy K. (2000). Tune In, Log On: Soaps, Fandom, and Online Community. Thousand Oaks, Sage.

Becker, Carl (1935). Everyman His Own Historian. New York, Crofts.

Benedict, Michael Les (1986). "Historians and the Continuing Controversy over Fair Use of Unpublished Manuscript Materials." American Historical Review 91(4): 859-881.

Bolter, Jay David and Richard Grusin (1996). "Remediation." Configurations 4(3): 311-358.

Carey, James (1989). Communication as Culture: Essays on Media and Society. New York, Routledge.

Charney, Leo and Vanessa Schwartz, Eds. (1995). Cinema and the Invention of Modern Life. Berkeley, University of California Press.

Crary, Jonathan (1992). Techniques of the Observer: On Vision and Modernity in the Nineteenth Century. Cambridge, MIT Press.

Derrida, Jacques (1995). "Archive Fever: A Freudian Impression.” Diacritics 25(2): 9-63.

Douglas, Susan (1987). Inventing American Broadcasting: 1912-1922. Baltimore, Johns Hopkins University Press.

Ernst, Wolfgang (1999). "Modular Readings (Writing the Monument): The case of Lapis Satricanus." Rethinking History 3(1): 53-73.

Fischer, Claude (1992). America Calling : A Social History of the Telephone to 1940. Berkeley, University of California Press.

Foucault, Michel (1972). The Archaeology of Knowledge. New York, Pantheon.

Guattari, Félix (1993). "Machinic Heterogenesis". In: V. Conley (ed.), Rethinking Technologies. Minneapolis, University of Minnesota Press.

Hayles, Katherine (1993). "Virtual Bodies and Flickering Signifiers." October 66(Fall): 69-91.

Johns, Adrian (1998). The Nature of the Book: Print and Knowledge in the Making. Chicago, University of Chicago Press.

LaCapra, Dominick (1988). History and Memory after Auschwitz. Ithaca, Cornell University Press.

LaCapra, Dominick (2001). Writing History, Writing Trauma. Baltimore, Johns Hopkins University Press.

Landow, George P. (1997). Hypertext 2.0. Baltimore, Johns Hopkins University Press.

Manovich, Lev (2001). The Language of New Media. Cambridge, MIT Press.

Miller, Daniel and Don Slater (2000). The Internet: An Ethnographic Approach. New York, Berg. 
Nelson, Theodor (1965). "A File Structure for the Complex, the Changing and the Indeterminate." Proceedings of the ACM National Conference: 84-100.

Novick, Peter (1988). That Noble Dream: The "Objectivity Question" and the American Historical Profession. New York, Cambridge University Press.

Plant, Sadie (1997). Zeroes + Ones : Digital Women + the New Technoculture. New York, Doubleday.

Poster, Mark (1997). Cultural History and Postmodernity : Disciplinary Readings and Challenges. New York, Columbia University Press.

Smith, Bonnie (1998). The Gender of History: Men, Women, and Historical Practice. Cambridge, Harvard University Press.

Spigel, Lynn (1992). Make Room for TV: Television and the Family Ideal in Postwar America. Chicago, University of Chicago Press.

Stephenson, Neal (1999). Cryptonomicon. New York, Harper Collins. 